\title{
NOCIÓN Y ELEMENTOS DE LA JUSTICIA AMBIENTAL: DIRECTRICES PARA SU APLICACIÓN EN LA PLANIFICACIÓN TERRITORIAL Y EN LA EVALUACIÓN AMBIENTAL ESTRATÉGICA
}

\author{
Dominique Hervé Espejo*
}

\begin{abstract}
RESUMEN
La justicia ambiental es un concepto que se incorpora al debate ambiental a fines de los años setenta en Estados Unidos. A partir de ese momento el concepto evoluciona desde una demanda politica a un objetivo del derecho ambiental. Los autores que han desarrollado el tema identifican diversos elementos en este concepto que delimitan su alcance y aplicación. En Chile se trata de una idea que recién se está explorando y que aún no se manifiesta ni en la política ni en la legislación ambiental nacional. En este trabajo se propone, a partir de la noción y elementos de justicia ambiental, la elaboración de directrices para el diseño de algunos instrumentos de gestión, tales como la planificación territorial y la evaluación ambiental estratégica, lo que permitiría incorporar el concepto concretamente en nuestro derecho ambiental.
\end{abstract}

\section{JUSTICIA AMBIENTAL- PLANIFICACIÓN TERRITORIAL- EVALUACIÓN AMBIENTAL ESTRATÉGICA}

Notion and elements of environmental justice: guidelines for its implementation in territorial planning and strategic environmental evaluation

\section{Abstract}

Environmental justice was a concept incorporated in environmental debates in the United States in the late seventies. Since then, this concept has evolved from a political demand to an objective in environmental law. The authors that have developed this subject identify different elements in the concept that delimit its reach and application. In Chile it is a recently explored idea and has not been yet manifested in politics or in national environmental legislation. This work suggests the elaboration of guidelines in territorial planning and strategic environmental evaluation, starting from notion and elements in environmental law, which will allow the thorough incorporation of this concept in our environmental law.

\section{ENVIRONMENTAL JUSTICE - TERRITORIAL PLANNING - STRATEGIC ENVIRONMENTAL EVALUATION}

* Abogada, Máster en Derecho, Profesora e investigadora de la Facultad de Derecho de la Universidad Diego Portales, Santiago de Chile. dominique.herve@udp.cl. Este trabajo se basa en la investigación desarrollada por la autora en el contexto del Proyecto Fondecyt N $^{\circ} 1090286$, "La aplicación del concepto de justicia ambiental en los instrumentos de gestión del espacio marino costero".

Artículo recibido el 8 de marzo de 2010 y aceptado para su publicación por el Comité Editorial el 28 de mayo de 2010 . 


\section{Palabras preliminares}

$\mathrm{Q}$ uizás la mejor forma de ilustrar de qué se trata la justicia ambiental y cuáles son sus elementos es a través de la referencia a casos concretos. Ejemplos de situaciones de injusticia ambiental en Chile abundan. Tales son, por nombrar algunos, la construcción de autopistas urbanas en Santiago ${ }^{1}$, la localización de vertederos y plantas de tratamiento de aguas servidas en la novena región de La Araucanía $^{2}$, la ubicación de las plantas de la industria salmonera en la décima región de Los Lagos ${ }^{3}$, o la zona de la quinta región correspondiente al complejo industrial de Ventanas y Puchuncaví ${ }^{4}$. Todos estos casos reflejan de una u otra manera una distribución inequitativa de los costos ambientales dentro de la sociedad, la ausencia de reconocimiento de la identidad de ciertas comunidades, la falta de acceso de las mismas a instancias públicas de participación en la toma de decisiones que afectan su calidad de vida y una marcada falta de valorización de la integridad de los ecosistemas.

Para explicar con mayor claridad la magnitud del problema que implica una situación de injusticia ambiental se analizará a continuación, brevemente, el caso de una zona de la ciudad de Santiago denominada "Rinconada de Maipú"5.

Rinconada de Maipú es una pequeña zona rural dentro de la Comuna de Maipú, de gran riqueza agrícola y en la que habitan aproximadamente tres mil quinientas personas. Destacan dentro de este sector la existencia de dos importantes plantas de tratamiento de aguas servidas, La Farfana y El Trebal. La primera sanea el 50\% de las aguas servidas de Santiago, y la segunda el 25\%. Por otro lado, en el mismo sector se ubica un relleno sanitario ("Santiago Poniente") que recibe cuarenta mil toneladas de residuos sólidos domiciliarios mensuales procedentes de ocho comunas de la capital. Por si fuera poco, los vecinos del lugar deben también aceptar la presencia de siete empresas extractoras

${ }^{1}$ Ver Universidad Diego Portales, Informe Anual sobre Derechos Humanos en Chile 2007. Hechos 2006. Capítulo de Medio Ambiente (Santiago, 2007), pp. 206-209. La construcción de autopistas urbanas en Santiago se propuso como una solución para disminuir la congestión vehicular y mejorar la calidad de vida de los habitantes de la ciudad. Sin embargo, estas obras han causado impactos socioeconómicos y ambientales en las comunidades aledañas a las autopistas, que han debido soportar los costos de esta iniciativa.

${ }^{2}$ Ver Universidad Diego Portales, Informe Anual sobre Derechos Humanos en Chile 2008. Hechos 2007. Capítulo de Medio Ambiente (Santiago, 2008), pp. 521-528. En la novena región se han generado importantes conflictos por la ubicación de basurales y plantas de tratamiento de aguas servidas que se han instalado al interior o de manera aledaña a comunidades mapuches, y que benefician a comunas de toda la región.

${ }^{3}$ Ibíd., pp. 528-534. Los diferentes proyectos que la industria salmonera ha desarrollado en la décima región han afectado, con particular fuerza, a ciertas comunidades huilliche ya que se han instalado a escasos metros de sus casas generando diversos impactos sociales y ambientales.

${ }^{4}$ Sobre este caso de concentración de industrias y centrales termoeléctricas en una zona, ver los trabajos publicados en Sabatini, F. y Sepúlveda, C. (Eds.), Conflictos Ambientales. Entre la Globalización y la Sociedad Civil (Publicaciones CIPMA, 1997), pp. 107-140; 141-156 y 195-218.

${ }^{5}$ La información que aquí se expone sobre este caso fue obtenida del análisis realizado durante el 2007 por la Clínica de Derechos Económicos, Sociales, Culturales y Ambientales de la Facultad de Derecho de la Universidad Diego Portales, al cual se hace referencia en el Informe Anual sobre Derechos Humanos en Chile 2008. Hechos 2007, pp. 510-521. 
de áridos y las descargas clandestinas de todo tipo de residuos en el Camino Rinconada. Los impactos ambientales provenientes de todas estas fuentes se manifiestan en malos olores, ruidos, contaminación del aire por material particulado, congestión vial por los camiones de basura que transitan constantemente por el lugar y, posiblemente, también la contaminación de las aguas subterráneas. Todos estos impactos generan importantes consecuencias en la salud y calidad de vida de las personas que habitan en dicha zona, fuera de eventuales daños a los terrenos agrícolas y a la naturaleza del lugar. La situación en que se encuentra esta comunidad evidentemente no es casualidad, sino que deriva de una serie de hechos y autorizaciones que han permitido este proceso de concentración de fuentes contaminantes. La comunidad ha intentado organizarse y reclamar ante las autoridades y las empresas; sin embargo, la existencia de divisiones internas y de diversos intereses económicos y políticos involucrados les ha impedido encauzar sus demandas de manera efectiva. Las autoridades, locales y regionales, no parecen haber tenido hasta la fecha un rol relevante en resolver este conflicto.

A simple vista, no cabe duda de que este caso representa una inadecuada distribución de los costos ambientales de una sociedad, la ausencia de mecanismos institucionales que permitan a los vecinos hacer valer sus pretensiones y derechos y una clara falta de respeto y de reconocimiento de la identidad de una comunidad de tradición agrícola. Cualquiera estaría de acuerdo en que aquí no se cumplen los estándares mínimos de justicia. A contrario sensu, una situación de justicia procuraría igualar las cargas de contaminación, el desarrollo nocivo y el agotamiento de los recursos entre todos los miembros de una sociedad, promoviendo una mayor participación de la comunidad en las decisiones que la puedan afectar y generando una sociedad y una institucionalidad en que se reconozca a todos sus miembros (individuos y comunidades), con sus diversidades, necesidades y capacidades.

En este contexto cabe preguntarse qué es la justicia ambiental. Si bien esta noción en Chile no forma parte del debate ambiental, autores de otras latitudes lo han analizado y definido desde distintos enfoques y aludiendo a diversos componentes. Por ejemplo, Bunyan Bryant distingue entre "racismo ambiental", "equidad ambiental” y "justicia ambiental" 6 . La primera acepción consiste en la decisión deliberada de situar a ciertos grupos en lugares cuyo uso no es deseado, llevando a una exposición desproporcionada de estos grupos a riesgos ambientales. La segunda, por su parte, consiste en la igual protección de las personas por parte de la legislación ambiental, y la tercera, esto es, la "justicia ambiental" propiamente tal, supone (según dicho autor) que todos tengan acceso a vecindarios seguros y limpios, trabajos adecuados, escuelas de buena calidad y comunidades sustentables.

Algunos también vinculan a la justicia ambiental con la teoría ecológica ya que, señalan, la teoría ecológica puede aportar información para entender por qué se distribuyen las cargas y beneficios ambientales entre los diversos grupos, etnias y clases

${ }^{6}$ Citado por Helfand, G. \& Peyton, J., “A Conceptual Model of Environmental Justice”, en Social Science Quarterly, Volume 80, N 1 (March 1999), p. 70. 
sociales ${ }^{7}$. Por otra parte, están también quienes abogan por el concepto de "justicia ecológica", incluyendo en el concepto de justicia ambiental la relación entre los seres humanos y el resto del mundo natural ${ }^{8}$.

Como se advierte, el concepto de justicia ambiental se ha desarrollado desde diversos enfoques. Para algunos podrá implicar igual calidad del medio ambiente para todos, para otros podrá requerir de ciertos mínimos ambientales que la legislación debe garantizar. Sin embargo, se puede coincidir en que todos estos enfoques han contribuido a crear un "movimiento social por la justicia ambiental", que se ha instalado con fuerza en la discusión pública de EE.UU. y, en menor medida, también en Europa. Atendido que la discusión de este tema en Chile recién comienza a expresarse, resulta útil revisar la evolución de este concepto en aquellos países donde ha pasado a ocupar un lugar central en la disciplina del derecho ambiental.

El objetivo de este trabajo es identificar los diversos elementos que constituyen el concepto de justicia ambiental de manera que se puedan aplicar a través de una política, legislación o instrumento de gestión ambiental. Para ello, después de una breve referencia a la noción y origen del concepto (2) se iniciará el análisis identificando sus elementos y aspectos esenciales, los que emanan de la teoría y doctrina especializada (3). A partir de la determinación de los elementos de la idea de justicia ambiental se pretende elaborar algunas directrices que permitan operativizar el concepto a través de dos instrumentos de gestión ambiental: la planificación territorial y la evaluación ambiental estratégica (4). Finalmente, se formularán conclusiones (5).

\section{NOCIÓN Y ORIGEN DEL CONCEPTO}

El concepto de la justicia ambiental surge en EE.UU. a fines de la década de los setenta como una manifestación de la nueva dirección que toman los grupos ambientalistas?.

${ }^{7}$ Bulletin of the Ecological Society of America, ECO JUSTICE. Relationships of Environmental Justice to Ecological Theory (April 2007), pp. 166-170. Aquí se sostiene que la teoría ecológica puede ayudar a clarificar la naturaleza del espacio en que ocurre la distribución de los beneficios y riesgos ambientales. Este documento desarrolla en particular la relevancia de la teoría de la "perturbación" o disturbance theory, que sostiene que ciertas perturbaciones naturales (por ejemplo, el fuego, el viento, la lluvia) son esenciales en los ciclos de los ecosistemas. La respuesta de los ecosistemas a estas perturbaciones es lo que se llama la capacidad de "resiliencia". A partir de estos supuestos se puede ayudar a explicar por qué la injusticia ambiental es persistente en ciertos espacios, y se puede además tener antecedentes científicos que provean de información para una adecuada planificación y manejo. Entre los antecedentes científicos que se pueden destacar para efectos de la justicia ambiental se distinguen los siguientes: diversas perturbaciones interactúan en los ecosistemas humanos; dichas perturbaciones son recurrentes en el tiempo; las perturbaciones son heterogéneas espacialmente; ciertos patrones de perturbaciones espaciales y temporales son característicos de ciertos paisajes.

${ }^{8}$ Ver, por ejemplo: Bosselman, K., "Ecological Justice and Law", en Richardson, B., \& Wood, S. (Eds.), Environmental Law for Sustainability (Hart Publishing, 2006), pp. 129-163; y Schlosberg, D., Defining Environmental Justice. Theories, Movements, and Nature (Oxford University Press, 2007).

${ }^{9}$ Arnold, C.A., "Land Use Regulation and Environmental Justice" 30 ELR (Environmental Law Reporter, 2000), p. 10395. 
En esa época el movimiento ambientalista norteamericano cambia su tradicional enfoque dirigido principalmente hacia la "conservación" de la vida silvestre por una preocupación hacia los grupos más vulnerables de la sociedad y su calidad de vida. Se reconoce entonces que estos grupos se han visto afectados especialmente por la contaminación ambiental y la depredación de los recursos naturales en los lugares en que viven, fenómeno cuyo origen se vincula con el desarrollo industrial ocurrido durante la mayor parte del siglo XX. Dicho desarrollo habría tenido lugar sin cortapisas ni regulaciones que permitieran la internalización de los costos de dicho proceso por parte de quienes los generaban ${ }^{10}$. Se inicia entonces un movimiento social por la justicia ambiental cuyo objetivo principal es obtener una distribución más equitativa de las cargas y beneficios ambientales ${ }^{11}$.

El movimiento ambientalista moderno norteamericano, que hace suyo el concepto de justicia ambiental, deriva de tres etapas diferentes ${ }^{12}$. La primera etapa tuvo lugar a comienzos del siglo XX, y su objetivo principal fue la conservación de los recursos naturales y la protección del medio ambiente puro o prístino. En EE.UU. este movimiento permitió, entre otros, el establecimiento de un sistema de áreas protegidas, la protección de los bosques y la designación de áreas de recreación natural. La segunda etapa comenzó durante los años sesenta, y su objetivo fundamental fue la obtención de reformas legislativas y el desarrollo regulatorio en materia ambiental ${ }^{13}$. La tercera y última etapa tuvo su origen a fines de los años setenta y su objetivo central ha consistido en llevar adelante demandas colectivas para proteger la salud humana de los efectos adversos de la contaminación del aire, del agua, de los pesticidas y sustancias químicas producidas por las industrias. Es decir, el movimiento ambientalista norteamericano evolucionó desde constituir un grupo compuesto esencialmente por conservacionistas y abogados, a transformarse en un movimiento social comunitario que aboga por los derechos y por la justicia ambiental.

Importante resulta revisar los principales hitos de la tercera etapa, con el objeto de explicar la evolución que ha experimentado este movimiento en EE.UU. En primer lugar se debe resaltar una declaración elaborada en 1991 por la "Primera Cumbre de Líderes Ambientales de Personas de Color"14. La Declaración establece 17 principios de justicia ambiental que incluyen, entre otros, los siguientes: el derecho fundamental a la autodeterminación política, económica, cultural y ambiental, de todos los pueblos; la responsabilidad estricta de todos los productores de residuos y sustancias tóxicas respecto de los daños

${ }^{10}$ Shrader-Frechette, K., Environmental Justice. Creating Equality, Reclaiming Democracy (Oxford University Press, New York, 2002), pp. 6 y ss.

${ }^{11}$ Para efectos de este trabajo se entenderá por "carga" ambiental a todo aquello que englobe tanto los costos y daños como los riesgos asociados al desarrollo de actividades que generan impactos ambientales. La idea de "beneficio" ambiental, por su parte, incluirá los servicios ambientales que un determinado ecosistema puede prestar.

${ }^{12}$ Hill, B., Environmental Justice, Legal Theory and Practice (Environmental Law Institute Press, 2009), pp. $1-4$.

${ }^{13}$ Es en esta época que surgen en EE.UU. las muy conocidas agrupaciones de abogados ambientalistas, tales como el Natural Resources Defense Council (NRDC), el Sierra Club o el Environmental Law Institute (ELI).

${ }^{14}$ Traducción propia de "First People of Color Environmental Leadership Summit". 
que causen; el derecho de las víctimas de la injusticia ambiental a recibir compensación y reparación plena; el derecho a participar como iguales en cualquier nivel de adopción de decisiones; y el derecho de los trabajadores a un ambiente sano y saludable ${ }^{15}$.

Es en este contexto que se hizo llegar a la EPA (Environmental Protection Agency) de EE.UU. la solicitud de adoptar medidas en el gobierno para enfrentar esta situación. A raíz de ello, la EPA creó un Grupo de Trabajo sobre "Equidad Ambiental"16 con el objeto de estudiar la afirmación consistente en que "las minorías raciales y la población de bajos ingresos soportan mayores riesgos ambientales que la población en general”. El Grupo de Trabajo produjo un informe en junio de 1992 titulado "Reducing Risk in All Communities", que confirmó el supuesto y estableció diez recomendaciones para enfrentar el tema. Una de ellas fue la creación de una oficina gubernamental a cargo de llevar adelante planes y políticas en la materia. Así, en noviembre de 1992 se creó la "Oficina de Equidad Ambiental" dentro de la EPA, la que más adelante, en 1994, pasó a llamarse "Oficina de Justicia Ambiental"17.

Otro de los hitos que cabe destacar en este proceso lo constituye la orden ejecutiva que el Presidente Clinton emitió en 1994 ( $\mathrm{N}^{\circ}$ 12898), titulada Federal Actions to Address Environmental Justice in Minority Populations and Low-Income Populations. Dicha orden estableció la obligación de que toda agencia federal debía desarrollar estrategias para lograr la justicia ambiental, mediante por lo menos las siguientes acciones: 1) la identificación de los efectos negativos desproporcionadamente altos en la salud humana y el medio ambiente, de sus programas, políticas y actividades relacionadas con grupos minoritarios o de bajos ingresos; 2) la promoción de la aplicación de los estatutos y estándares ambientales y de salud en áreas con población de bajos ingresos o de minorías raciales; 3) asegurar mayor participación pública; 4) mejorar la investigación y la información relacionada con la salud y el ambiente de las poblaciones de bajos ingresos y grupos minoritarios; y 5) identificar modelos diferenciados de consumo de recursos naturales dentro de las poblaciones de bajos ingresos y grupos minoritarios ${ }^{18}$. Dentro de los aspectos más relevantes de esta orden ejecutiva destaca el que se haya utilizado el concepto de justicia ambiental aplicándolo no sólo a los grupos de minoría racial sino que a todo grupo de bajos ingresos. De esta manera, se incorporó en la demanda por justicia ambiental a todos los grupos vulnerables de la sociedad, independiente del hecho de la

${ }^{15}$ El listado completo de los principios se puede encontrar en la siguiente dirección de internet: http:// www.ejrc.cau.edu/princej.html

${ }^{16}$ Como se verá más adelante la "equidad" ambiental no es lo mismo que la "justicia" ambiental, en la medida que este último concepto comprende a su vez otros elementos además de la "equidad" propiamente tal.

17 Véase http://www.epa.gov/oecaerth/basics/ejbackground.html

${ }^{18}$ A su vez, la orden ejecutiva estableció un Grupo de Trabajo Gubernamental en Justicia Ambiental, dirigido por el Director de la EPA e integrado por los jefes de 11 agencias federales, entre las que destacan los Departamentos de Justicia, Defensa, Energía, Trabajo, Interior, Transporte, Agricultura, Vivienda y Urbanismo, Comercio y Salud. 
existencia o no de una discriminación racial ${ }^{19}$. Evidentemente, al tratarse de una orden del gobierno la política ambiental norteamericana incorporó este objetivo dentro de sus metas oficiales.

Así las cosas en EE.UU., la situación en Europa fue y es diferente. A pesar de que el derecho europeo ha sido un referente en el desarrollo del derecho ambiental general, no ha experimentado con la misma fuerza que los EE.UU. la incorporación de este concepto, ni la sociedad ha experimentado un movimiento social por la justicia ambiental equivalente al del país norteamericano. Sin embargo, a partir de la década de los 90 el debate ha adquirido mayor relevancia, en particular en el Reino Unido ${ }^{20}$. Los antecedentes disponibles permiten establecer que así como en EE.UU., en el Reino Unido son las comunidades más pobres las que se ven afectadas por los niveles más altos de contaminación atmosférica, de ruido, de agua, o tienen menor acceso a espacios verdes o seguridad en los vecindarios $^{21}$. Sin embargo, a diferencia de los EE.UU., el debate se ha centrado más en la situación socioeconómica de las comunidades afectadas que en su origen racial. Es por ello que, de acuerdo con quienes han investigado el tema, no se ha vinculado el trabajo de las organizaciones que promueven la protección del medio ambiente con aquellas organizaciones que luchan en contra de la discriminación. Esta situación probablemente ha generado que los instrumentos legales de la UE que permiten velar por la no discriminación no se hayan utilizado con el objeto de promover la justicia ambiental ${ }^{22}$. De esta manera, el debate en materia de justicia ambiental en Europa se ha orientado fundamentalmente hacia los aspectos contenidos en el Convenio de Aarbus sobre el Acceso a la información, la Participación del público en la toma de decisiones y el Acceso a la justicia de medio ambiente, suscrito en junio de $1998^{23}$. Todos estos aspectos están relacionados con el ámbito procedimental de la justicia ambiental, ámbito que por lo tanto ha sido discutido y aplicado en la mayor parte de los

${ }^{19}$ Fue quizás el hecho de la vinculación original en EE.UU. entre el movimiento por la justicia ambiental y la discriminación racial lo que permitió que este debate se instalara con más fuerza que en los países europeos. En efecto, el origen de este movimiento en EE.UU. se encuentra en las comunidades de color que se ven afectadas directamente por las situaciones de contaminación ambiental. En cambio, la inquietud por estos temas en Europa se desarrolla a un nivel distinto, básicamente por profesionales del medio ambiente que no se ven necesariamente afectados por situaciones de injusticia ambiental.

${ }^{20}$ Dobson, A., Justice and the Environment. Conceptions of Environmental Sustainability and Dimensions of Social Justice (Oxford University Press, 1998), pp. 26-29.

${ }^{21}$ Schwarte, C. \& Adebowale, M., Environmental Justice and Race Equality in the European Union (Capacity Global, 2007), p. 15. Disponible en www.capacity.org.uk

${ }^{22}$ Por ejemplo, en Inglaterra existe un instrumento (Race Relations Amendments Act) que exige a todas las autoridades públicas que implementen evaluaciones de impacto sobre la igualdad racial, con el objeto de prevenir la posibilidad de que una política pueda afectar desfavorablemente a ciertos grupos raciales. Sin embargo, este instrumento no ha sido utilizado para evaluar los impactos ambientales negativos de ciertas políticas sobre grupos específicos (Ibíd.).

${ }^{23}$ Este Convenio fue suscrito en la ciudad de Aarhus, Dinamarca, y entró en vigencia en octubre del año 2001. 
países europeos. Sin embargo, con la excepción del Reino Unido, no existe gran evidencia de un debate similar en materia de justicia distributiva y medio ambiente ${ }^{24}$.

Por último, cabe referirse a la justicia ambiental en el ámbito global. Sin perjuicio de que este debate ha tenido su origen a nivel doméstico en los EE.UU., también se ha desarrollado una discusión paralela en el contexto internacional. Dicha discusión tiene su base en los reclamos efectuados contra los gobiernos y las corporaciones multinacionales por los abusos en que han incurrido históricamente con respecto a los pueblos indígenas y a las condiciones de pobreza de los países en desarrollo ${ }^{25}$. Sin embargo, en el último tiempo el debate internacional sobre la justicia ambiental se ha desarrollado en foros internacionales especializados, tales como aquellos relacionados con el comercio internacional $^{26} \mathrm{y}$, fundamentalmente, en las negociaciones que han tenido lugar en la última década con respecto al cambio climático ${ }^{27}$. En efecto, el término de “justicia climática” es ya un concepto utilizado comúnmente y que alude tanto a la distribución de los riesgos provenientes del cambio climático como a la diferenciación en las obligaciones que deben asumir los países de acuerdo con su cuota de responsabilidad en el problema ${ }^{28}$. A su vez, como una manifestación más de la "injusticia ambiental" se ha determinado que los pueblos, comunidades y países más pobres serán los principales afectados por este fenómeno, ya sea porque sus economías se encuentran más expuestas a sufrir efectos provenientes de

${ }^{24}$ Sin perjuicio de que esta ha sido la tendencia, en la actualidad existen algunas iniciativas y publicaciones que dan cuenta del debate incipiente que se está desarrollando en Europa en esta materia. Por ejemplo, en Alemania, cabe citar diversos artículos y un libro de Ralph Czarnecki (identificados en www. ralphczarnecki.de); y en Inglaterra, recientemente fue publicado un artículo de Jane Holder titulado "Building Spatial Europe: An Environmental Justice Perspective”, en Scott, J. (Ed.), Environmental Protection: European Law and Governance (Oxford University Press, 2009).

${ }^{25}$ Kuehn, R., “A Taxonomy of Environmental Justice”, en 30 ELR (Environmental Law Reporter, 2000) p. 10682 .

${ }^{26}$ Un ejemplo muy claro de esta tendencia se manifiesta en las diversas movilizaciones ciudadanas que han tenido lugar con el objeto de demandar mayor justicia social y ambiental en el contexto de la labor de la Organización Mundial del Comercio (OMC). Ver: Carruthers, D., "Popular Environmentalism and Social Justice in Latin America" en: Carruthers, D. (Ed.), Environmental Justice in Latin America. Problems, Promise and Practice (The MIT Press, Cambridge Massachusetts \& London, England, 2008), pp. 11-12.

${ }^{27}$ Ver, por ejemplo: Paterson, M., "Principles of Justice in the Context of Global Climate Change", y Wiegandt, E., "Climate Change, Equity and International Negotiations", ambas en Luterbacher, U. \& Sprinz, D. (Eds.), International Relations and Global Climate Change (The MIT Press, Cambridge, Massachusetts \& London, England, 2001).

${ }^{28}$ Aquí se alude al principio de derecho internacional ambiental denominado "responsabilidad común pero diferenciada”, acuñado por la Declaración de Río de 1992 y luego en diversos tratados internacionales, tales como la Convención Marco de Cambio Climático del mismo año y el Protocolo de Kyoto de 1997. El principio 7 de la Declaración sostiene: Los Estados deberán cooperar con espíritu de solidaridad mundial para conservar, proteger y restablecer la salud y la integridad del ecosistema de la Tierra. En vista de que han contribuido en distinta medida a la degradación del medio ambiente mundial, los Estados tienen responsabilidades comunes pero diferenciadas. Los países desarrollados reconocen la responsabilidad que les cabe en la búsqueda internacional del desarrollo sostenible, en vista de las presiones que sus sociedades ejercen en el medio ambiente mundial y de las tecnologías y los recursos financieros de que disponen. 
los riesgos naturales, como por carecer de recursos suficientes para adaptarse y mitigar los impactos provenientes del cambio climático en cuestión ${ }^{29}$.

Los hechos históricos recientemente descritos permiten distinguir tres ejes conceptuales en los que se ha desarrollado el debate en materia de justicia ambiental. Estos son: la raza o el origen étnico (en EE.UU.); la condición socioeconómica (en Europa); y las diferencias entre los países desarrollados y en desarrollo (en el ámbito internacional). De los tres ejes mencionados se puede extraer un elemento común: la existencia de diferencias en la distribución de las cargas y beneficios ambientales entre los sujetos de una comunidad, ya sea nacional o internacional.

\section{Elementos ESENCiALES DEL CONCEPTO DE JUSTiCiA AMBiENTAL}

Como se verá a continuación el elemento de "justicia distributiva” es el contenido central, pero no el único, del concepto de justicia ambiental.

Por justicia ambiental se entenderá la distribución equitativa de las cargas y beneficios ambientales entre todas las personas de la sociedad, considerando en dicha distribución el reconocimiento de la situación comunitaria y de las capacidades de tales personas y su participación en la adopción de las decisiones que los afectan.

Precisada la noción de justicia ambiental, cabe referirse y analizar los elementos constitutivos de ella para justificar, en primer lugar, por qué se ha adoptado esta noción y no otra diversa y, en segundo lugar, para derivar directrices destinadas a su implementación.

La distribución de las cargas ambientales, así como de los beneficios que el medio ambiente brinda, constituye, en realidad, una pregunta propia de lo que se entiende por “justicia distributiva”. Esta pregunta tiene cada vez más relevancia en la medida que los bienes ambientales son más escasos y las posibilidades de cargas e impactos sobre los mismos son, por el otro lado, cada vez mayores ${ }^{30}$.

Sin embargo, existen también otros aspectos de la justicia ambiental que escapan a la justicia distributiva y que se han incorporado al debate por aquellos autores que sostienen que la desproporción en las cargas ambientales constituye un efecto, y no la

${ }^{29}$ Grupo Intergubernamental de Expertos sobre Cambio Climático, “Informe de Síntesis”, publicado en 2007, disponible en: www.ipcc.ch/pdf/assessment-report/ar4/syr/ar4_syr_sp.pdf . Por ejemplo, cabe transcribir la siguiente frase del Informe (p. 19): "Distribución de impactos y de vulnerabilidades: Existen marcadas diferencias entre regiones, y las de economía más débil suelen ser las más vulnerables al cambio climático".

${ }^{30}$ La justicia distributiva tiene que ver con la adecuada (proporcional) distribución de los bienes y cargas sociales disponibles. Una de las consecuencias más importantes de sostener que las cargas ambientales deben ser distribuidas proporcionalmente entre los distintos miembros de la sociedad es que todo tratamiento diferenciado requiere de justificación, es decir, toda distribución desigual importará un traspaso de la carga de la prueba al discriminador. Sólo mediante el aseguramiento de este aspecto se proveería a la gente de varias regiones geográficas, particularmente aquellas habitadas por pobres, con la presunción de que deben ser tratados igualitariamente. Véase Shrader-Frechette, K., ob. cit. ( $\left.\mathrm{N}^{\circ} 10\right)$, p. 27. 
causa de la injusticia ambiental, la que se manifiesta de distintas maneras y no solamente desde la perspectiva del uso indeseado del territorio o de la inequitativa distribución de los riesgos ambientales. En efecto, dichos autores sostienen que la injusticia ambiental se expresa sobre todo en la ausencia de oportunidades o "participación" política y de "reconocimiento" de los que la sufren, elementos que de existir les permitirían desafiar los mecanismos estructurales de decisión establecidos por la sociedad ${ }^{31}$.

De esta manera, el concepto de justicia ambiental presenta diversas esferas aunque todas relacionadas entre sí. Algunos autores, como Shrader-Frechette, identifican dos aspectos esenciales en el concepto. Por un lado, el aspecto del tratamiento equitativo que tiene directa relación con la idea de justicia distributiva; y, por el otro, el aspecto de la participación significativa que apunta, a su vez, a la idea de justicia participativa ${ }^{32}$. Kuehn, en cambio, propone categorizar los elementos de la justicia ambiental en cuatro: justicia distributiva; justicia procedimental; justicia correctiva, y justicia social ${ }^{33}$. Bullard establece que los principios de justicia ambiental se pueden categorizar en un marco de cinco características: la protección de todas las personas de la degradación ambiental; la adopción de un enfoque de prevención del daño a la salud; la atribución de la carga de la prueba a quienes contaminan; la eliminación de la necesidad de probar la intención de discriminar, y la reparación de las inequidades existentes mediante acciones dirigidas y recursos suficientes ${ }^{34}$. Schlosberg, por su parte, distingue elementos adicionales a los ya mencionados. Tales son los aspectos que dicen relación con el "reconocimiento" y con las "capacidades" ("capabilities") 35.

Quizás la definición más conocida de "justicia ambiental” es la que da la EPA, la que adhiere al enfoque que distingue dos aspectos esenciales: distribución y participación. Así sostiene que se trata del "trato justo y participación significativa de todas las personas, sin importar su raza, color, nacionalidad, o nivel de ingresos, en el desarrollo, implementación y aplicación de las políticas, leyes y regulaciones ambientales” ${ }^{36}$. Luego define en particular "trato justo" y "participación significativa" 37.

31 Tales elementos (la participación política y el reconocimiento) son necesarios para asegurar la existencia de instituciones y procedimientos que garanticen a todas las personas la igualdad de oportunidades en la toma de decisiones. De otra forma, las víctimas de la desigualdad de oportunidades tienen mayores probabilidades de experimentar explotación, marginalización, impotencia y violencia.

32 Shrader-Frechette, K., ob. cit. ( $\left.\mathrm{N}^{\mathrm{o}} 10\right)$, pp. 23 y ss.

33 Véase Kuehn, R., ob. cit. ( $\left.\mathrm{N}^{\circ} 25\right)$, p. 10681 y ss.

${ }^{34}$ Bullard, R., "Environmental Justice for All”, en Unequal Protection: Environmental Justice E Communities of Color, 1996. Citado por Kuehn, R., ob. cit. (No 25), p. 10683.

${ }^{35}$ Schlosberg, D., ob. cit. ( $\left.\mathrm{N}^{\circ} 8\right)$, p. 12.

36 Traducción propia de la definición en inglés: "fair treatment and meaningful involvement of all people regardless of race, color, national origin, or income with respect to the development, implementation, and enforcement of environmental laws, regulations, and policies". Definición extraída del documento elaborado por el National Environmental Justice Advisory Council, "Meaningful Involvement and Fair Treatment by Tribal Environmental Regulatory Programs” (November, 2004), p. 5. Disponible en: http:/www.epa.gov/compliance/resources/ publications/ej/nejusticia ambientalc/ips-final-report.pdf

${ }^{37}$ A continuación las definiciones en inglés dadas por la EPA. "Fair treatment" means that no group of people, including racial, ethnic, or socioeconomic groups, should bear a disproportionate share of the negative environmental 
A continuación se explicará en qué consisten los elementos que se han considerado esenciales por los diversos autores para definir el concepto de justicia ambiental. De allí se busca extraer aquellas directrices que deben estar presentes cuando se invoca o se aplica dicho concepto. El objetivo de esta sección es simplemente ilustrar el estado del debate en torno al contenido del concepto de justicia ambiental y de sus principales componentes. Cabe señalar que el análisis de los elementos de la justicia ambiental está basado en aquellos elementos propios de la teoría de la justicia desarrollados por la Teoría Política ${ }^{38}$.

Se distinguirán a continuación aquellos elementos de la teoría de la justicia que se extrapolan a la justicia ambiental, de aquellos elementos propios de la justicia ambiental, que se agregan por parte de la doctrina especializada.

\subsection{Elementos de la teoría de la justicia que se extrapolan a la justicia ambiental}

Los elementos de la teoría de la justicia que se extrapolan a la justicia ambiental son la equidad o justicia distributiva, el reconocimiento, la participación y las capacidades.

\section{a. La equidad o justicia distributiva}

La Teoría Política ha definido el concepto de justicia casi absolutamente basada en el concepto de "equidad" en la distribución de los bienes. Para Rawls, justicia es el estándar sobre el cual los aspectos distributivos de la estructura básica de la sociedad deben ser evaluados ${ }^{39}$. En efecto, el objetivo de Rawls fue desarrollar los principios básicos de la justicia con el objeto de establecer criterios destinados a aplicarse en relación con la estructura básica de la sociedad ${ }^{40}$. Para encontrar dichos principios, según él, hay que

consequences resulting from industrial, municipal, and commercial operations or the execution of federal, state, local, and tribal environmental programs and policies. "Meaningful involvement" means that: 1) potentially affected community residents have an appropriate opportunity to participate in decisions about a proposed activity that will affect their environment and/or health; 2) the public's contribution can influence the regulatory agency's decision; 3) the concerns of all participants involved will be considered in the decision-making process; and 4) the decision makers seek out and facilitate the involvement of those potentially affected. En: Hill, B., ob. cit. (No 12), p. 8.

38 Bullard, Dobson, Kuehn, Schlosberg, Shrader-Frechette, entre otros, se refieren a la teoría de la justicia como el marco teórico en el que se debe analizar el concepto de justicia ambiental. De esta manera toman como punto de partida de su análisis lo que sostienen los teóricos de la justicia. En particular se repiten las referencias a los trabajos de John Rawls, Iris Young, Nancy Fraser, Amartya Sen, Martha Nussbaum y Ronald Dworkin. No es objeto de este trabajo analizar directamente lo planteado por los teóricos de la justicia, sino simplemente indicar su influencia en el debate en materia de justicia ambiental.

${ }^{39}$ Citado por Schlosberg, D., ob. cit. ( $\left.\mathrm{N}^{\circ} 8\right)$, p. 12.

${ }^{40}$ Gargarella, R., Las Teorías de la Justicia después de Rawls. Un breve manual de filosofía política (Editorial Paidós Estado y Sociedad, España, 1999), p. 35. Una cita textual de la obra de Rawls que hace Gargarella y permite entender mejor el concepto de justicia de este autor es la siguiente: "El objeto primario de la justicia es la estructura básica de la sociedad o, más exactamente, el modo en que las instituciones sociales más importantes distribuyen los derechos y deberes fundamentales y determinan la división de las ventajas provenientes de la cooperación social. Por instituciones más importantes entiendo la constitución política y las principales disposiciones económicas y sociales". 
situarse en una posición de igualdad que él llama "posición original" imaginaria en la que los individuos se encuentran detrás de un "velo de ignorancia", lugar en el que no pueden orientar su decisión a su propio favor debido a que no se conocen las propias fortalezas y debilidades, ni la posición que se ocupa en la sociedad, ni las propias concepciones del bien. De esa manera se pueden desarrollar principios de justicia desde una posición imparcial. Cabe señalar que Rawls presupone que tales seres imaginarios se encuentran motivados para obtener cierto tipo particular de bienes, que él denomina "bienes primarios", que serían aquellos bienes básicos indispensables para satisfacer cualquier plan de vida ${ }^{41}$.

Desde esa posición, Rawls argumenta que los individuos determinarían la existencia de dos principios básicos de justicia: todos tienen los mismos derechos políticos (libertades básicas); y la distribución de la inequidad social y económica debe beneficiar o ser ventajosa para todos ${ }^{42}$. Este último principio parte de la base de que las mayores ventajas de los más beneficiados por la lotería natural son justificables sólo si ellas forman parte de un esquema que mejora las expectativas de los miembros menos aventajados de la sociedad $^{43}$. Por lo tanto, la noción de Rawls de "justicia” como "equidad” implica entender a la justicia como las reglas que deben aplicarse a la distribución justa de los bienes sociales, económicos y políticos ${ }^{44}$. La importancia de la teoría liberal de la justicia es que el concepto de equidad o distribución justa se desliga de cualquier acuerdo sustantivo sobre qué es lo que se cree que es "bueno". Lo relevante son las "reglas" de la distribución ${ }^{45}$. Por lo tanto, este concepto de justicia es imparcial y más bien procedimental ${ }^{46}$. Con posterioridad a Rawls, diversos teóricos de la justicia han seguido el camino de definir este concepto a partir de cómo y qué se "distribuye" para construir una sociedad justa ${ }^{47}$.

Como se verá más adelante, cuando se trate en particular el elemento o el enfoque de la "justicia ecológica”, la teoría de John Rawls no parece ser suficiente para explicar el elemento distributivo de justicia ambiental, en la medida que solamente apunta a un aspecto procedimental o formal de distribución, y no al contenido o sustancia de la misma. La distribución equitativa de las cargas y beneficios ambientales, en cambio, parte de la base de que dicha distribución es "buena" para la sociedad, cuestión que escapa a la teoría rawlsiana de justicia.

${ }^{41}$ Ibid., p. 37 . Los "bienes primarios" de Rawls son de dos tipos: los de tipo social (como la riqueza, las oportunidades, los derechos); y los de tipo natural (como los talentos, la salud, la inteligencia).

${ }^{42}$ Con posterioridad Rawls agrega a su teoría otros elementos, dentro de los que cabe mencionar para efectos de este trabajo al llamado savings principle, al que se hará referencia más adelante.

43 Gargarella, R., ob. cit. ( $\left.\mathrm{N}^{\circ} 40\right)$, p. 39.

${ }^{44}$ Schlosberg, D., ob. cit. ( $\left.\mathrm{N}^{\circ} 8\right)$, p. 13.

45 Ibid.

${ }^{46}$ En efecto, la teoría de Rawls surge en oposición al concepto utilitarista de “justicia” que se fija más bien en el resultado del proceso distributivo.

${ }^{47}$ Véase Gargarella, R., ob. cit. ( $\left.\mathrm{N}^{\circ} 40\right)$. 


\section{b. El reconocimiento}

El enfoque principalmente distributivo de la justicia por parte de Rawls y otros teóricos posteriores ha sido impugnado fundamentalmente por Iris Young y Nancy Fraser. Dichas autoras promueven la necesidad de realizar un examen de las "causas" de la mala distribución en la sociedad, cuestión que no puede realizarse a través de una posición original imaginaria, sino que debe basarse en la realidad. Para ellas el punto central es el "reconocimiento". En otras palabras, la causa de la "inequidad" distributiva es la ausencia del reconocimiento social y político, manifestado a través de la desvalorización individual y cultural de ciertas personas y comunidades ${ }^{48}$. Qué se entiende por "reconocimiento" es a su vez objeto de discusión por diversos autores. Algunos consideran central en este concepto el aspecto sicológico del mismo, es decir, la valorización de una persona provendría del reconocimiento dado por los otros ${ }^{49}$. De esta manera, la ausencia de reconocimiento sería un daño y una causa de injusticia, de la misma manera que la ausencia de una distribución adecuada. Por otro lado, hay quienes consideran que la falta de reconocimiento es una práctica más bien institucional que una experiencia individual, de manera que la falta de reconocimiento consistiría en un daño al "status" social más que un daño sicológico ${ }^{50}$. Sin perjuicio de que en este trabajo se considera el reconocimiento como un elemento independiente que compone el concepto de justicia, algunos autores se han preguntado si el reconocimiento es más bien un aspecto que constituye una condición previa a la situación de igualdad de la posición imaginaria de Rawls o, si por el contrario, se trata de uno de los bienes que se van a distribuir. Rawls al menos no parece dejarlo claro dentro de la formulación y evolución de su teoría, lo que ha implicado que diversos autores, con posterioridad, hayan elaborado distintas posiciones al respecto.

En cuanto elemento de la justicia ambiental, el reconocimiento apunta a la valorización de ciertas comunidades o grupos vulnerables de la sociedad y, a su vez, a la valorización de la naturaleza y de los ecosistemas en sí mismos.

\section{c. La participación}

Brevemente se dirá que la participación es considerada como un elemento esencial de la justicia. En lo que dice relación con el derecho ambiental, el derecho a la participación y el acceso a la información es quizás uno de los aspectos más universalmente aceptados como un contenido propio de la disciplina. La participación, en el contexto de la teoría de la justicia, consiste en el mecanismo o procedimiento necesario para lograr una mejor distribución y un mayor reconocimiento. En efecto, para diversos autores, una

${ }^{48}$ Schlosberg, D., ob. cit. (No 8), pp. 13-14.

49 Ibid., pp. 16-17.

${ }^{50}$ Fraser identifica tres procesos relacionados con el "status" basados en la ausencia de reconocimiento. Estos son: la práctica general de dominación cultural; un modelo de no reconocimiento equivalente a ser considerado "invisible"; y la falta de respeto o la sistemática representación en estereotipos públicos y culturales (Ibid.). 
teoría de la justicia debe también focalizarse en el proceso político y democrático, que permite establecer estructuras institucionales para hacer frente tanto a los problemas de distribución como de reconocimiento ${ }^{51}$.

\section{d. Las capacidades}

Por último, existen también autores como Sen y Nussbaum que postulan una teoría de la justicia que va más allá del enfoque distributivo y que sostienen que se debe evaluar si una distribución es justa considerando cómo ésta afecta las "capacidades", el bienestar, la posibilidad de una persona de realizarse en la sociedad. Por lo tanto, la justicia no es sobre "cuánto" se tiene, sino que sobre "si" se tiene aquello que es necesario para llevar una vida conforme a las propias elecciones ${ }^{52}$.

Si bien es posible identificar estos elementos esenciales del concepto de justicia en la noción de justicia ambiental, dichos elementos no son suficientes para entender completamente el concepto, sino que se hace necesario recurrir a elementos que vienen en denominarse "elementos propios de justicia ambiental".

\subsection{Elementos propios de la justicia ambiental}

Los elementos que aquí se consideran propios de la justicia ambiental son el elemento "colectivo" y el elemento "ecológico".

\section{a. Elemento colectivo}

En general, la teoría de la justicia se ha elaborado desde una perspectiva liberal que considera la justicia respecto de los "individuos", y no en relación con los "grupos" o "comunidades". Sin perjuicio de ello, es evidente que muchas injusticias se cometen con respecto a ciertos grupos vulnerables más que respecto de los individuos que las conforman. De ahí que algunos autores hayan querido abordar de manera más amplia el elemento de las "capacidades" considerando que debe incluir también la forma de realización de los grupos y comunidades ${ }^{53}$. En efecto, la realidad lleva a concluir que los propios grupos demandan justicia respecto de sus respectivas comunidades como tales. En cuanto a la justicia ambiental esta es una de las características claves. Las situaciones de injusticia ambiental se producen respecto de grupos y comunidades antes que individuos.

\footnotetext{
${ }^{51}$ Schlosberg, D., ob. cit. ( $\left.\mathrm{N}^{\circ} 8\right)$, pp. 25-28.

52 Ibid., pp. 29-34.

53 Ibid., pp. 34-38.
} 


\section{b. Elemento ecológico}

Hasta ahora los elementos de la justicia ambiental que se han explicado se refieren a una relación entre seres humanos. Aquellos que consideran que la justicia ambiental incluye también la relación de los seres humanos con el mundo natural postulan el concepto de "justicia ecológica". Para algunos autores, sin embargo, la relación de los seres humanos con el resto del mundo natural no es un asunto de la "justicia" sino que de la "moral" o de la "ética". El objetivo de esta parte del trabajo es presentar los argumentos que se han esbozado para determinar si las responsabilidades y obligaciones que se tienen con el futuro y el resto del mundo natural pueden incluirse dentro del concepto de "justicia", y en particular de "justicia ambiental".

Este debate tiene mucho en común y tiende a confundirse con aquel que distingue entre aquellos que conciben el derecho ambiental desde una perspectiva "antropocéntrica" y aquellos que lo conciben, en cambio, desde un enfoque "ecocéntrico". Desde la perspectiva de la teoría de la justicia, estos diferentes enfoques son esenciales ${ }^{54}$.

Para los primeros, es decir, los antropocentristas, el tema "ambiental" debe incorporarse dentro de lo que Rawls llama "comprehensive ideals", consistentes en posibles concepciones de lo que se entiende como "bueno" dentro de una sociedad y que compiten democráticamente ${ }^{55}$. En cambio, para los autores ecologistas, la relación de los seres humanos con el mundo natural se encuentra más cercano a lo que Rawls llamó "public reason arguments" que constituyen los principios básicos que se consideran neutrales dentro de una sociedad ${ }^{56}$. Por ejemplo, según Wissenburg, el "savings principle" que Rawls agrega a su teoría de la justicia permitiría incorporar el medio ambiente dentro de estos últimos, en la medida, que dicho principio alude a la justicia intergeneracional como condición de la posición original en que se encuentran aquellos que distribuyen los bienes detrás del velo de la ignorancia. Sostiene que sin la existencia de este principio no podría existir justicia en una sociedad ya que habría privilegios para las generaciones actuales en desmedro de las generaciones futuras ${ }^{57}$. En la práctica, este principio se traduciría en lo que Wissenburg llama "principle of restraint", que exige que los derechos deben ser distribuidos de tal manera que se mantengan disponibles para una futura redistribución. En otros términos, consiste en la obligación de no destruir bienes en aquellos casos en que sean irreemplazables ${ }^{58}$.

Sin perjuicio de lo anterior, la mayoría de los autores ecologistas van más allá y su objetivo no consiste en hacer calzar sus demandas por justicia ecológica dentro de los sistemas ya elaborados de la teoría de la justicia, sino que, por el contrario, pretenden modificar el sistema liberal imperante. Según Bosselmann, existen así algunos autores

${ }^{54}$ Bosselmann, K., ob. cit. (No 8), p. 130.

55 Ibid., p. 133.

${ }^{56}$ Bosselmann, K., ob. cit. (No 8), p. 133.

57 Wissenburg, M., "An Extension of the Rawlsian Savings Principle to Liberal Theories of Justice in General”, en Dobson, A. (Ed.), Fairness and Futurity. Essays on Environmental Sustainability and Environmental Justice (Oxford University Press, 1999), p. 174.

${ }^{58}$ Ibid., pp. 190-196. 
que han querido reconceptualizar la "justicia" desde su posición ecologista ${ }^{59}$, tales como Schlosberg y el mismo Bosselmann. El primero sostiene, al igual que lo hizo con respecto al concepto más tradicional de justicia ambiental, que para conceptualizar una teoría que haga justicia con la naturaleza se debe ir más allá del enfoque distributivo que la mayor parte de los autores da al concepto de justicia. De esta manera, desarrolla nuevamente con respecto a la "justicia ecológica" los elementos del "reconocimiento", las "capacidades" y la "participación" 60 . Así extiende el "reconocimiento" de manera de incorporar en dicho elemento al mundo natural tanto por su valor en sí mismo como por su importancia para el mundo humano. En cuanto a las "capacidades", sostiene que incluye todo aquello que sea necesario para el pleno funcionamiento tanto del mundo humano como del "no humano". Es decir, dicho elemento se refiere a la plenitud del proceso de la vida en general. Por último, con respecto a la "participación" como elemento que permite incluir tanto el reconocimiento como las capacidades del mundo natural no humano, sostiene la necesidad de extender la legitimación activa, el acceso a la información ambiental y, sobre todo, la consideración del mundo natural en el proceso humano de adopción de decisiones.

Por su parte, Bosselmann presenta como esencial al concepto de "justicia ecológica" el reconocimiento de tres principios ${ }^{61}$, los de "justicia intrageneracional” (dimensión social de la justicia ecológica); "justicia intergeneracional” (obligación de mantener la integridad ecológica en la medida que no sabemos qué necesitarán las futuras generaciones. Este principio puede responder tanto a un enfoque antropocéntrico como ecocéntrico), y "justicia interespecies" (preocupación por el mundo natural no humano). La importancia de adoptar este enfoque de la justicia ecológica es el establecer criterios que permiten regular la relación entre la justicia intra e intergeneracionales, en la medida que en la sociedad existen distintas prioridades en competencia. Aquí entra al debate el concepto universalmente aceptado de desarrollo sustentable ${ }^{62}$, el que no puede hacerse cargo de este problema puesto que en teoría da igual relevancia al ámbito social, económico y ambiental, los que deben ser ponderados y equilibrados. Lo anterior implicaría mantener, de alguna manera, los modelos actuales de desarrollo en que finalmente prima la idea de un crecimiento económico sustentable ${ }^{63}$. En cambio, la incorporación del principio de justicia interespecie permite adoptar un concepto de "sustentabilidad fuerte" que establece la preferencia por la sustentabilidad ecológica o las necesidades de las futuras generaciones. Según Bosselmann, la "integridad ecológica” debe ser el estándar con que se mida cualquier forma de desarrollo, y la "justicia

59 Bosselmann, K., ob. cit. ( $\left.\mathrm{N}^{\circ} 8\right)$, pp. 137-142.

${ }^{60}$ Schlosberg, D., ob. cit. ( $\left.\mathrm{N}^{\circ} 8\right)$, pp. 129 y ss.

${ }^{61}$ Bosselmann, K., ob. cit. ( $\left.\mathrm{N}^{\circ} 8\right)$, pp.150-155.

${ }^{62}$ El concepto de desarrollo sustentable fue acuñado por el "Informe Brundlandt" elaborado por distintas naciones en 1987 para la ONU. Originalmente se llamó Nuestro Futuro Común (Our Common Future, en inglés). En este informe se utiliza por primera vez el término definiéndolo como aquel que satisface las necesidades del presente sin comprometer las necesidades de las futuras generaciones. Implica un marco conceptual que en teoría da igual énfasis a la sustentabilidad ambiental y al contexto económico y social del desarrollo.

${ }^{63}$ Esta idea alude a la conocida discusión que enfrenta al concepto de "sustentabilidad débil”, como sería en este caso, con un concepto de "sustentabilidad fuerte". 
interespecie" el estándar de cualquier concepto de justicia ecológica. Lo anterior implica el reconocimiento del valor intrínseco de la naturaleza y, por lo tanto, la adopción de un enfoque ecocéntrico ${ }^{64}$. Estos principios no son inocuos en la medida que permiten contar con una mejor base para el diseño y aplicación de las políticas y normativas ambientales, y mejorar los procesos y los resultados en materia de adopción de decisiones. De esta manera, se postula la necesidad de trabajar en un concepto que haga justicia tanto a los seres humanos como al resto del mundo natural.

La tarea de definir "justicia ambiental” en toda su magnitud no es, por lo tanto, una tarea fácil. Dificulta aún más el trabajo el que no sólo el concepto de "justicia” sino que también el de "medio ambiente" sea un concepto amplio y controvertido, que ha dado lugar a diversas teorías sobre su contenido y elementos ${ }^{65}$. Pareciera ser que, entonces, la intersección entre ambos necesariamente dará también como resultado un concepto amplio y discutible $e^{66}$.

En todo caso no cabe duda de que, en el debate conceptual sobre los elementos de la justicia ambiental, para todos los autores la equidad en la distribución es el elemento crucial del concepto ${ }^{67}$. La diferencia se produce en los distintos énfasis que algunos autores, desde sus propias perspectivas, dan a aquellos otros elementos que consideran deben sumarse al de la distribución equitativa de las cargas y beneficios ambientales.

${ }^{64}$ En la misma línea cabe citar lo expuesto por Vicente Giménez, T., en su artículo "El Nuevo Paradigma de la Justicia Ecológica”, en: Justicia Ecológica y Protección del Medio Ambiente (Editorial Trotta, Madrid, 2002), pp. 66-67. Dicha autora sostiene que "la determinación de lo justo o lo debido en cuanto objeto de la justicia ecológica (...) requiere la configuración del ecosistema como paradigma sociocultural, capaz de describir el conjunto de límites a las necesidades del hombre y de la sociedad. Pero tales límites no significan un freno o una llamada a la resignación y el estancamiento respecto a la actividad humana económica, social y cultural, sino que consiste en el reconocimiento de los condicionamientos y las resistencias de las realidades físicas y biológicas que han de constreñir los proyectos de desarrollo”.

${ }^{65}$ En Chile, la Ley de Bases del Medio Ambiente (Ley N ${ }^{\circ}$ 19.300) de 1994 define "medio ambiente" en su artículo 2 letra 1l) como el sistema global constituido por elementos naturales y artificiales de naturaleza física, química o biológica, socioculturales y sus interacciones, en permanente modificación por la acción bumana o natural y que rige y condiciona la existencia y desarrollo de la vida en sus múltiples manifestaciones. Esta definición jurídica refleja una concepción amplia de ambiente, que incorpora el entorno artificial o construido, y el cultural, además del entorno natural. Otras definiciones elaboran un concepto más restringido, tal como el que da el catedrático español Ramón Martín Mateo que reduce el medio ambiente a los tres medios ambientales a través de los que se desplaza o deposita la contaminación, esto es, agua, aire y suelo. Citado por Bermúdez, J., Fundamentos de Derecho Ambiental (Ediciones Universitarias de Valparaíso, 2007), p. 54.

${ }^{66} \mathrm{Al}$ respecto, ver Dobson, A., ob. cit. ( $\left.\mathrm{N}^{\circ} 20\right)$. El autor analiza las concepciones que derivan de la intersección entre las distintas dimensiones de la "sustentabilidad ambiental" y de la "justicia social". Concluye que, sin perjuicio de que las agendas de la sustentabilidad ambiental y de la justicia social tienen objetivos diferentes, existen puntos en que se intersectan y que permiten la formulación de una idea de justicia ambiental que incluye la justicia respecto del mundo natural no humano.

${ }^{67}$ Cabe señalar que no se debe confundir el concepto simplemente con una distribución de la "contaminación existente", sino que también con el objetivo de lograr una disminución de la contaminación. Aspecto que resalta Hill en su libro, a través de la siguiente cita, "what is ultimately at stake in the environmental justice debate is everyone's quality of life. The goal is equal protection, not equal pollution", en Hill, B., ob. cit. ( $\left.\mathrm{N}^{\circ} 12\right)$, p. 4. 
Finalmente, a partir de lo expuesto en las secciones anteriores se puede afirmar que la justicia ambiental consiste en la distribución equitativa de las cargas y beneficios ambientales entre todas las personas de la sociedad, considerando en dicha distribución el reconocimiento de la situación comunitaria y de las capacidades de tales personas y su participación en la adopción de las decisiones que los afectan. Asimismo, la decisión que se adopte debe garantizar la integridad ecosistémica de la zona afectada.

Esta definición se tendrá presente en la elaboración de las directrices que sigue a continuación.

\section{Directrices derivadas de la justicia ambiental aplicables a los INSTRUMENTOS DE GESTIÓN AMBIENTAL}

En esta parte se analizará la aplicación de los elementos de la justicia ambiental a dos instrumentos de gestión ambiental. El objetivo de este ejercicio es argumentar que la demanda por justicia ambiental puede ser, además de un reclamo político de grupos ambientalistas, un objetivo perseguido por la política y el derecho ambiental ${ }^{68}$.

El trabajo se centrará en dos instrumentos en particular, que por sus características y objetivos son capaces de constituir herramientas idóneas para lograr el objetivo de la justicia ambiental. Estos son los mecanismos para regular el "uso del suelo" y el instrumento conocido como "evaluación ambiental estratégica". En efecto, dichos instrumentos pueden constituir una fórmula clave para enfrentar la injusticia ambiental desde un enfoque preventivo y proactivo, a diferencia de los múltiples mecanismos jurídicos que se han intentado hasta ahora para remediar este tipo de situaciones ${ }^{69}$.

A continuación se formula un intento por incorporar los elementos del concepto de justicia ambiental al diseño y aplicación de dichos instrumentos.

${ }^{68}$ En este sentido, véase Slater, A. \& Pedersen, O., "Environmental justice: lessons on definition and delivery from Scotland", Journal of Environmental Planning and Management (2009, 52:6), pp. 797-812. En este artículo se analiza la evolución que han tenido el Gobierno y el Parlamento de Escocia, en los últimos años, en elaborar políticas y leyes que incorporan elementos sustantivos (no puramente procedimentales) del concepto de justicia ambiental.

${ }^{69}$ Arnold, C.A., ob. cit. (No9), pp. 10395-10396. Por ejemplo, en EE.UU. el mecanismo más utilizado ha sido interponer acciones judiciales y/o reclamos administrativos en defensa de los derechos de los afectados por este tipo de conflictos. Situación que también se da en Chile. Por ejemplo, un caso paradigmático en este sentido es el de la comunidad indígena Pepiukelen de Pargua, X región de Los Lagos, que desde el año 2001 ha interpuesto una serie de acciones judiciales con el objeto de evitar la construcción de plantas de la industria salmonera y otros megaproyectos, dentro y en las cercanías de sus territorios ancestrales, todas las cuales han sido desestimadas (ver el capítulo de Medio Ambiente del Informe Anual sobre Derechos Humanos en Chile 2008. Hechos 2007, de la Facultad de Derecho de la Universidad Diego Portales). 


\subsection{Instrumentos de Planificación Territorial}

La "planificación" consiste en el proceso de identificar y establecer objetivos para el futuro, en el desarrollo de políticas o planes para lograr dichos objetivos, y en la elaboración de mecanismos específicos para la aplicación de tales planes ${ }^{70}$. La Asociación Americana de Planificación define "planificación" como el proceso comprehensivo, coordinado y continuo, cuyo objetivo es ayudar a quienes toman las decisiones, ya sean públicas o privadas, a llegar a decisiones que promuevan el bien común de la sociedad ${ }^{71}$. Dentro de los principales objetivos de interés público que comprende la planificación se identifican al menos los siguientes: la salud, la seguridad, la conservación de los recursos naturales, la calidad ambiental, la equidad social ${ }^{72}$.

La planificación del uso del suelo es un elemento esencial de la planificación, ya que se interrelaciona con todos los objetivos recién mencionados. En efecto, el enfoque actual en materia de planificación territorial, al menos en el derecho comparado, incorpora esta característica y propone una "planificación espacial integrada" que promueve las sinergias entre las políticas sectoriales a través de una estrategia territorial ${ }^{73}$. Este enfoque tiene ventajas que hasta la fecha algunos sistemas de planificación no incluyen. Cabe destacar dentro de las principales, las siguientes: la coordinación entre los diversos actores involucrados en la planificación; la gestión del desarrollo de una determinada zona, más que simplemente determinar cuáles son los usos posibles; y la posibilidad de hacerse cargo de los efectos contradictorios de las políticas sectoriales.

En el ordenamiento jurídico chileno, la forma de hacer efectiva la planificación del uso del suelo es a través de los llamados "Instrumentos de Planificación Territorial (IPT)" y, más específicamente, a través de las "autorizaciones” o "permisos" que se requieren para desarrollar determinadas actividades. Estas autorizaciones son por regla general competencia de la autoridad local (municipalidad) y deben ser otorgadas en conformidad con las reglas establecidas en los IPT.

De acuerdo con la Ley General de Urbanismo y Construcciones (LGUC) y su Ordenanza ${ }^{74}$, en Chile existen diversos IPT, cada uno con diferentes ámbitos de extensión territorial: nacional, regional, intercomunal y comunal ${ }^{75}$. Así, se reconoce la planificación urbana a nivel nacional (aunque en la práctica nunca se ha aprobado), a nivel regional (planes regionales de desarrollo urbano), a nivel intercomunal (Plan Regulador Intercomunal o Metropolitano) y comunal (Plan Regulador Comunal). Se establece la prevalencia de los

\footnotetext{
${ }^{70}$ Ibid., p. 10404.
}

${ }^{71}$ Ibid. La definición en inglés es: "A comprehensive, coordinated and continuing process, the purpose of which is to help public and private decision makers arrive at decisions which promote the common good of society".

72 Ibid.

${ }^{73}$ Holder, J. \& Lee, M., Environmental Protection, Law and Policy, Second Edition, Text and Materials (Cambridge University Press, 2007), pp. 522 y ss.

${ }^{74}$ DFL N $^{\circ} 458$ de 1976 (modificada por última vez mediante Ley $\mathrm{N}^{\circ} 20.218$ de 2007) y DS No 47 de 1992 del Ministerio de Vivienda y Urbanismo (modificada por última vez mediante DS No 143 de 2007).

75 Artículo 28, Ley General de Urbanismo y Construcciones. 
instrumentos de mayor nivel, por lo que lo dispuesto en un plan intercomunal prima sobre el plan comunal ${ }^{76}$. Cabe asimismo destacar que el ordenamiento territorial en nuestro país obedece principalmente a objetivos urbanísticos. Es decir, busca establecer los diversos usos del suelo en una zona urbana. Excepcionalmente se aplican los IPT al suelo rural, ya sea a través de los planes reguladores intercomunales que incluyen zonas rurales (entre zonas urbanas incluidas en el plan) o a través del instrumento que permite el cambio de uso del suelo fuera de los límites urbanos.

Esta situación genera un vacío regulatorio en materia de uso del suelo que en la práctica se viene a llenar con las legislaciones sectoriales respectivas. Dicho de otra manera, debido a que el ordenamiento jurídico nacional reconoce además de las competencias regulatorias sobre el uso del suelo una serie de competencias sectoriales respecto del uso de determinados recursos, en aquellos casos donde no hay norma del uso del suelo se aplica la normativa sectorial. Por otra parte, esta misma situación produce que incluso donde sí hay norma de uso de suelo se genere una superposición de competencias y normativas aplicables respecto de un mismo recurso. Esto es lo que ocurre, por ejemplo, en cuanto al uso de las aguas, las costas, las playas, todos recursos cuyo uso implica definiciones en materia de uso del suelo. El problema es que muchas veces las decisiones son adoptadas por la autoridad sectorial respectiva sin tener presente la multiplicidad de usos que compiten dentro de una misma zona. De ahí que se ha sostenido que el ordenamiento territorial nacional se ha visto afectado por "las tensiones derivadas de la presión concurrente sobre un mismo territorio de distintos usos y competencias de los órganos públicos"77.

La experiencia nacional en esta materia no es ajena a lo que ha ocurrido en otros países. Así, por ejemplo, Inglaterra, que cuenta con uno de los sistemas de control del uso del suelo más sofisticados del mundo ${ }^{78}$, ha tardado en incorporar un enfoque integrado y coordinado en materia de planificación ${ }^{79}$.

Sin duda es precisamente este hecho uno de los factores que ha permitido que existan tantas situaciones de injusticia ambiental en la sociedad. Efectivamente, uno de los riesgos ambientales que en primer lugar inciden en la vigencia de la justicia ambiental es el de la localización de usos no deseados del suelo ${ }^{80}$. Por lo mismo es que la regulación del uso del suelo debiera constituir un instrumento idóneo o adecuado para hacerse cargo de este tema.

${ }^{76} \mathrm{Al}$ respecto ver: Cordero, E., "El derecho urbanístico, los instrumentos de planificación territorial y el régimen jurídico de los bienes públicos", en Revista de Derecho de la Pontificia Universidad Católica de Valparaíso XXIX (Valparaíso, Chile, $2^{\circ}$ semestre 2007), pp. 269-298.

77 Ibid., p. 271.

$78 \mathrm{Al}$ respecto ver una explicación sobre la legislación inglesa en materia de "town and country planning” en: Bell, S. \& McGillivray, D., Environmental Law, Sixth Edition (Oxford University Press, 2006), pp. 441-506.

${ }^{79}$ Recién lo ha incorporado en el 2004 mediante el Planning and Compulsory Purchase Act, que implica una modificación del tradicional sistema de planificación inglés (Town and Country Planning Act).

${ }^{80}$ Esta situación en inglés es conocida como locally unwanted land uses, o LULU's. 
Los IPT tienen, por lo tanto, gran relevancia e inciden directamente en la calidad de vida de la población local y en el manejo del medio ambiente de una zona. Sus disposiciones, a su vez, van a tener efecto directamente en el crecimiento y desarrollo de un lugar y en el manejo de las infraestructuras. De esta manera, si se incorporaran en su elaboración y aplicación los diversos elementos de la justicia ambiental, se favorecería que de los distintos usos que se pueden dar a un espacio se elija aquel que permita un mejor aprovechamiento y distribución del mismo, teniendo en cuenta sus condiciones ecológicas, sociales y económicas.

Arnold concuerda con esta idea en la medida que sostiene que es la misma planificación del uso del suelo la que debe hacerse cargo de revertir la distribución inequitativa de patrones de zonificación ${ }^{81}$. Este autor identifica como una de las principales causas de la injusticia ambiental la existencia de ciertos patrones de zonificación que son inequitativos, y que han contribuido precisamente a la generación de la exclusión de los grupos sociales más débiles. De esta manera, en la medida que han sido los propios instrumentos de planificación territorial (y las decisiones judiciales que han interpretado los conflictos que han surgido a su respecto ${ }^{82}$ ) los que históricamente han ido causando las actuales situaciones de injusticia ambiental, son estos mismos instrumentos los que pueden en la actualidad hacerse cargo de revertirla.

Para ello, se deben desarrollar ciertas directrices que tomen en cuenta los elementos de la justicia ambiental al momento de elaborar y aplicar un IPT. Algo así como "indicadores" de justicia ambiental. Por ejemplo, aquí se postulan los siguientes:

- la consideración de información científica relacionada con los ecosistemas presentes en una zona. La consideración de las características ecológicas de un determinado territorio puede ayudar a identificar las actividades cuyo desarrollo sería perjudicial o positivo tanto para el medio ambiente del lugar como para la situación económica y social respectiva. Aquí el estándar mínimo sería la mantención de la integridad ecosistémica.

- la separación de usos incompatibles. Por ejemplo, la separación de actividades que supongan respecto de un mismo recurso un riesgo ambiental y un servicio

81 Arnold, C.A., ob. cit. (Nº 9), pp. 10398 y ss.

${ }^{82}$ Cabe mencionar la famosa sentencia de la Corte Suprema de EE.UU. en el caso Village of Euclide, Obio v. Ambler Realty Co. de 1926, que dio lugar al término "Euclidean Zoning". Esta sentencia respaldó la constitucionalidad de la zonificación, instrumento diseñado para separar los diferentes usos de suelo considerados como incompatibles. Sin embargo, la aplicación de este instrumento dio lugar a un patrón del uso del suelo que generó segregación socioeconómica o racial en los EE.UU. (Ver Salkin, P., "Environmental Justice and Land Use Planning and Zoning”, en Government Law Center of Albany School, Government Law Online, Spring 2004, p. 438). Por su parte, la jurisprudencia chilena en materia de uso del suelo no ha tenido consecuencias relevantes en torno a las situaciones de injusticia ambiental. Una excepción la constituye la sentencia de la Corte Suprema (Rol No 1219, de fecha 22 de junio de 2009) que acogió un recurso de protección por vulneración al derecho a vivir en un medio ambiente libre de contaminación, en relación al otorgamiento de una autorización ambiental a una termoeléctrica (Campiche) en la zona de Ventanas. La Corte sostiene que la eliminación ilegal de un uso de suelo para áreas verdes en una localidad afectada por altas emisiones de contaminantes provoca un menoscabo evidente en el entorno de quienes recurren. 
ambiental. Tal es el caso de una industria que elimina desechos líquidos en un río (vg. industria de celulosa) y otra actividad que necesita de la calidad de las aguas para su desarrollo (vg. actividad agrícola).

- la concentración de usos similares. El uso de un determinado territorio con actividades que significan riesgos ambientales similares. Por ejemplo, la autorización de áreas aptas para la acuicultura dentro de una misma zona, de manera que las externalidades negativas de dicha actividad generen un impacto localizado. Este criterio, sin embargo, presenta también inconvenientes puesto que si no se evalúan adecuadamente los impactos acumulativos que se generen, tanto en el espacio como en el tiempo, esta misma regla puede ocasionar el efecto contrario, esto es, situaciones de injusticia ambiental (vg. la zona de Ventanas y Puchuncaví donde se concentran actividades contaminantes similares, tales como diversas centrales termoeléctricas).

- la reserva de espacios. La destinación de ciertas áreas prioritarias, por su valor ecosistémico, para su conservación.

- la planificación integrada del uso del territorio. Esta regla implica que los IPT deben adoptar un enfoque integrado de la planificación, de manera de incorporar en su elaboración los diversos usos que las políticas y legislaciones sectoriales dan a los recursos existentes en una zona. Por ejemplo, los IPT debieran incorporar las indicaciones en materia de usos preferentes que establecen las zonificaciones regionales del uso del borde costero.

- la coordinación entre las diversas autoridades competentes. En la elaboración de los IPT deben intervenir todas las autoridades con competencia sectorial sobre los recursos de una zona.

- la participación. La utilización de los IPT debiera permitir que las comunidades participen con anticipación en la determinación de las normas y reglas que se aplicarán en el desarrollo de los territorios en que habitan, y no solamente actúen con posterioridad para oponerse a un proyecto o instalación ${ }^{83}$.

\subsection{Evaluación Ambiental Estratégica}

La Evaluación Ambiental Estratégica (EAE) consiste en "aplicar los principios de la Evaluación de Impacto Ambiental (EIA) a políticas gubernamentales (ambientales y no ambientales), planes (sectoriales y territoriales) y programas de acción" ${ }^{4}$. Se trata de evaluar ambientalmente actividades que se sitúan por sobre el nivel de proyectos individuales de inversión. Su origen se remonta a la National Environmental Policy Act de 1969,

${ }^{83}$ Para ilustrar este punto cabe transcribir una cita de Arnold, que sostiene: "land use planning and regulation foster choice, self-determination, and self-definition for local neighborhoods, not paternalism that insists that there is a single correct environmental justice goal" (Arnold, C.A., ob. cit. ( $\mathrm{N}^{\circ}$ 9), p. 10427).

${ }^{84}$ Clark, B.D., “Alcance y objetivos de la Evaluación Ambiental Estratégica”, en Estudios Públicos, 65, (verano 1997), Santiago, Chile, p. 2. 
en EE.UU., que incorpora dentro del sistema jurídico norteamericano la Evaluación de Impacto Ambiental, incluyendo dentro de las actividades a evaluar las "acciones federales” mayores. Bastante más tarde es incorporada en la Unión Europea, ya que sólo se pudo establecer la exigencia de la evaluación ambiental de planes y programas mediante la Directiva 2001/42/EC, que entró a regir en el 2004. Su ámbito de acción deja fuera a las "políticas", incluyendo sólo ciertos planes y programas.

Este instrumento tiene una serie de beneficios o ventajas para la gestión ambiental ${ }^{85}$. Por ejemplo, se aplica antes que se elaboren los proyectos individuales, de manera que se puede influenciar el tipo de proyectos que se quiere lograr. Por otro lado, permite evaluar impactos que son difíciles de considerar a nivel de proyecto, tales como los impactos acumulativos sobre el medio ambiente o los grandes impactos sobre la biodiversidad o el cambio climático. Quizás el aspecto más relevante es que permite evaluar mejor las alternativas que existen para el desarrollo de determinadas actividades, puesto que una vez que se evalúan los proyectos individuales por regla general hay ciertas alternativas que ya han sido descartadas.

Mediante este instrumento, quienes adoptan decisiones de nivel político y/o programático tienen mayor información acerca de las dimensiones ambientales de las mismas, de manera de considerarlas junto con las otras dimensiones que involucran este tipo de decisiones (económicas y sociales). Las etapas de la EAE son las mismas que las de la EIA, es decir ${ }^{86}$ :

- la determinación de si una acción determinada debe someterse o no a la EAE. Se puede utilizar el mecanismo de listados, al igual que en la EIA, pero en este caso de políticas, planes y programas. Otro enfoque consiste en analizar caso a caso si éstas tienen efectos ambientales significativos ${ }^{87}$;

- la identificación de los problemas claves y alternativas que deben ser abordados en la evaluación;

- la recopilación de información para describir el medio ambiente o línea base. En este caso como se trata de un área geográfica amplia, la recopilación se concentra en los elementos claves del medio ambiente, y se trata de información más general y no de detalle como en el caso de los proyectos de inversión;

- la predicción y evaluación de los impactos ambientales de la actividad. En este caso cobran especial relevancia los impactos acumulativos tanto en el espacio como en el tiempo;

- la participación de la ciudadanía;

- la decisión final. Aquí se plantea un problema ya que el proponente de la acción (política, plan o programa) es una autoridad pública, que debe someter la

\footnotetext{
${ }^{85}$ Holder, J. \& Lee, M., ob. cit. (N $\left.\mathrm{N}^{\circ} 73\right)$, pp. 597 y ss.

${ }^{86}$ Clark, B.D., ob. cit. (No 84), pp. 4-6.

${ }^{87}$ Al respecto ver: Bermúdez, J., ob. cit. (No 65), pp. 205-206.
} 
evaluación de su actividad a otra autoridad. Por lo tanto, se deben establecer arreglos institucionales que permitan garantizar la revisión de la acción por una autoridad independiente;

- el monitoreo o seguimiento de la decisión.

Las mayores diferencias entre la EIA y la EAE son la escala y oportunidad del estudio, así como el grado de detalle que se requiere ${ }^{88}$. La escala es mayor en la EAE ya que comprende varias actividades, con amplitud de alternativas, en un área más extensa y la gama de impactos ambientales puede ser mayor. Las diferencias de oportunidad se refieren a que el intervalo de tiempo entre el proceso de planificación y la implementación de la actividad específica que da origen al impacto ambiental en la EAE es mayor, por lo que la incertidumbre también.

La EAE se puede aplicar ya sea a políticas o planes sectoriales (por ejemplo, una política sobre el manejo de los recursos hídricos) o a políticas o planes que se vayan a aplicar en un mismo espacio o región (desarrollos multisectoriales dentro de un área geográfica $)^{89}$. El primer enfoque ayuda a seleccionar el tipo de proyectos que se buscan (en el sector hídrico, por ejemplo, hidroelectricidad vs. agricultura vs. acuicultura vs. turismo). El segundo enfoque permite evaluar los impactos acumulativos tanto espacial como temporalmente (considerando los impactos de proyectos futuros, presentes y pasados).

La EAE de las políticas o planes que se aplican a una zona determinada implica la evaluación ambiental de una planificación territorial integrada, a la que se hizo referencia en la sección anterior. Pero la justicia ambiental no se trata sólo de ordenamiento territorial. Por el contrario, muchos casos de justicia ambiental tienen que ver con el uso de otros recursos distintos al suelo. Un caso paradigmático en Chile es el de la política sectorial en cuanto al uso y aprovechamiento del agua.

En efecto, Chile adoptó en 1981 un Código de Aguas que modificó sustancialmente la política estatal en esta materia. Se reforzaron los derechos de propiedad privada, aumentando la autonomía privada en el uso de las aguas, y se crearon mecanismos de mercado basados en separar los derechos de agua de la propiedad de la tierra ${ }^{90}$. Se crearon derechos no consuntivos sobre las aguas, los que tienen por objeto promover el desarrollo hidroeléctrico del país. Sin embargo, no se incluyeron mecanismos que permitieran el manejo de las cuencas hidrográficas por parte de la autoridad, ni se establecieron requisitos en materia de calidad de las aguas, lo que favoreció el abuso de ciertos usos del recurso por parte de los titulares de los derechos. La modificación legal del 2005 cambió en parte este sistema, otorgando mayores competencias a la autoridad pública, la que ahora puede exigir un caudal mínimo ecológico para otorgar derechos de agua y, además, se establece el pago

${ }^{88}$ Clark, B.D., ob. cit. ( $\left.\mathrm{N}^{\circ} 84\right)$, pp. 7-8.

${ }^{89}$ Ibid., pp. 15-17.

${ }^{90}$ Bauer, C., Contra la Corriente. Privatización, mercados de agua y el Estado en Chile (Lom Ediciones, 2002), p. 57. 
de patentes por el no uso de los derechos, lo que busca impedir la especulación que se había originado a partir del Código de 1981. Sin perjuicio de ello, los derechos de agua se mantienen mayoritariamente en manos de las empresas mineras e hidroeléctricas, dejando que las comunidades tradicionales y las poblaciones indígenas, a las que se restringe el acceso a este recurso, paguen los "costos" de las ganancias económicas y políticas del desarrollo" . Este caso ejemplifica una situación de injusticia ambiental generada por una política sectorial que no previó los impactos ambientales y sociales que causaría.

Cabe señalar que la legislación ambiental en Chile no exige la EAE de políticas, planes y programas, con la sola excepción de los IPT. En efecto, la Ley N N 19.300 sobre Bases Generales del Medio Ambiente consagra el Sistema de Evaluación de Impacto Ambiental (SEIA) en sus artículos 8 y siguientes como un sistema de evaluación ambiental de proyectos. Así, en el artículo 10 se incluye un listado de los proyectos que deben ingresar al Sistema, todos los cuales constituyen proyectos individuales de inversión, ya sean públicos o privados, con la única excepción de lo dispuesto por la letra h). Esta disposición señala que deben ingresar al SEIA los "Planes regionales de desarrollo urbano, planes intercomunales, planes reguladores comunales, planes seccionales, proyectos industriales o inmobiliarios que los modifiquen o que se ejecuten en zonas declaradas latentes o saturadas"92. Es decir, a través de esta fórmula se ha logrado la evaluación ambiental de los instrumentos de planificación territorial, lo que constituye en la práctica una especie de evaluación ambiental estratégica. Sin embargo, las disposiciones que se aplican a esta evaluación son las mismas que se establecen para la evaluación de proyectos de inversión, cuestión que implica que no se evalúen necesariamente las variables que deben considerarse en una EAE.

Al igual que en el caso de los IPT, se considera que la EAE es un instrumento adecuado para hacerse cargo de los distintos elementos de la justicia ambiental. En efecto, el sometimiento de políticas, planes y programas a una evaluación ambiental estratégica podría evitar la generación de impactos ambientales desproporcionados, velando por la participación y el reconocimiento de la situación particular de ciertas comunidades. Las

${ }^{91}$ Wickstrom, S., "Cultural Politics and the Essence of Life: Who Controls the Water?", en: Carruthers, D., ob. cit. ( $\left.\mathrm{N}^{\circ} 26\right)$, pp. 291-294.

92 El Proyecto de Ley que crea el Ministerio, el Servicio de Evaluación Ambiental y la Superintendencia del Medio Ambiente, Boletín No 5.947-12, ingresado el 3 de julio de 2008 a la Cámara de Diputados, y que actualmente se encuentra en segundo trámite constitucional, incorpora la Evaluación Ambiental Estratégica, pero con carácter voluntario. Solo se mantiene obligatorio para los IPT. Así, agrega un artículo 7 bis a la Ley 19.300 que señala: Se someterán a evaluación ambiental estratégica las políticas y planes de carácter normativo general, así como sus modificaciones sustanciales, que tengan impactos sobre el medio ambiente o la sustentabilidad, que el Presidente de la República, a proposición del Consejo de Ministros, señalado en el artículo 72, decida.

En todo caso, siempre deberán someterse a evaluación ambiental estratégica los planes regionales de ordenamiento territorial, planes intercomunales, planes reguladores comunales y planes seccionales, planes de desarrollo urbano y zonificaciones del borde costero y del territorio marítimo. En esta situación el procedimiento y aprobación del instrumento estará a cargo del Ministerio de Vivienda, el Gobierno Regional o el Municipio o cualquier otro organismo de la administración del Estado, respectivamente. 
directrices que se propone debieran aplicarse en la EAE para cumplir con los objetivos de la justicia ambiental son, por ejemplo:

- Incluir dentro del listado de políticas, planes y programas que deben someterse a una EAE aquellos que generen riesgos o impactos sobre comunidades que constituyen minorías étnicas y sobre comunidades de bajos ingresos;

- Incluir también aquellas políticas, planes y programas que impliquen la concentración de actividades contaminantes en una zona determinada;

- Evaluar si existen alternativas que generen menos problemas de justicia ambiental que la política, plan o programa propuesto. Es decir, este criterio implica que en la evaluación se logre garantizar que la política o plan propuesto no va a generar nuevos problemas de justicia ambiental o que no va a empeorar los problemas ya existentes;

- Aprobar políticas, planes o programas en la medida que acrediten un trato justo para todas las personas, independiente de su raza, cultura o nivel de ingreso.

\section{Conclusiones}

No cabe duda que tanto en Chile como en el resto del mundo existen graves situaciones de injusticia ambiental. En este trabajo se parte de la base de que el derecho ambiental y los instrumentos jurídicos que lo componen constituyen uno de los mecanismos para hacerse cargo de dicho problema.

Para ello es necesario tener presente y entender los diferentes enfoques de la justicia ambiental y los elementos que la integran. Dicha tarea no es fácil. Como se vio a lo largo de este trabajo, la justicia ambiental es un concepto amplio, discutible y, a veces, abstracto.

El concepto de justicia ambiental es, en este sentido, similar al concepto del "desarrollo sustentable", ya que su contenido depende de la interpretación que los diversos autores o, en su caso, las distintas políticas públicas y normativas asignen a cada uno de sus elementos. Sin embargo, aquí se sostiene que su análisis y delimitación conceptual a través de ciertas directrices permitirá concretizar la demanda por justicia ambiental mediante mecanismos jurídicos específicos que ayudarán a consagrar tal concepto como un objetivo jurídico y social, además de un objetivo político.

La planificación territorial y la evaluación ambiental estratégica son instrumentos de gestión que permiten incorporar, tanto en su diseño como en su aplicación, un enfoque de justicia ambiental. Esto porque se trata de mecanismos preventivos que permiten identificar y proyectar, a partir de determinados criterios, los usos del territorio y el manejo de los recursos naturales y de las actividades económicas que los impactan. La tarea consiste en elaborar las directrices de justicia ambiental que permitan incluir los elementos de dicho concepto en tales instrumentos de gestión. Algunas de estas directrices se han propuesto aquí. 


\section{BIBLIOGRAFÍA}

Arnold, C.A., "Land Use Regulation and Environmental Justice", 30 ELR (Environmental Law Reporter), 2000, pp. 10395-10433.

Bauer, C., Contra la Corriente. Privatización, mercados de agua y el Estado en Chile (Lom Ediciones, 2002), 207 pp.

Bell, S. \& McGillivray, D., Environmental Law, Sixth Edition (Oxford University Press, 2006), $910 \mathrm{pp}$.

Bermúdez, J., Fundamentos de Derecho Ambiental (Ediciones Universitarias de Valparaíso, 2007), $285 \mathrm{pp}$.

Bosselmann, K., "Ecological Justice and Law". En: Richardson, B. \& Wood, S. (Eds.), Environmental Law for Sustainability (Hart Publishing, Oxford and Portland Oregon, 2006), pp. 129-163.

Bulletin of the Ecological Society of America, Eco-Justice. Relations of Environmental Justice to Ecological Theory, April 2007, pp. 166-170.

Carruthers, D.V. (Ed.), Environmental Justice in Latin America. Problems, Promise and Practice (The MIT Press, Cambridge, Massachusetts, London, England, 2008), 329 pp.

Clark, B.D., "Alcance y objetivos de la Evaluación Ambiental Estratégica”, en Estudios Públicos, 65 (verano 1997), Santiago, Chile, 22 pp.

Cordero, E., "El Derecho Urbanístico, los Instrumentos de Planificación Territorial y el Régimen Jurídico de los Bienes Públicos". En: Revista de Derecho de la Pontificia Universidad Católica de Valparaíso XXIX (Valparaíso, Chile, 2do Semestre de 2007), pp. 269-298.

Dobson, A., Justice and the Environment. Conceptions of Environmental Sustainability and Dimensions of Social Justice (Oxford University Press, 1998), 280 pp.

Dobson, A. (Ed.), Fairness and Futurity. Essays on Environmental Sustainability and Social Justice (Oxford University Press, 1999), 328 pp.

Gargarella, R., Las Teorías de la Justicia después de Rawls. Un breve manual de filosofía política, Editorial Paidós Estado y Sociedad, España, 1999, 223 pp.

Grupo Intergubernamental de Expertos sobre Cambio Climático, "Informe de Síntesis", publicado en 2007, disponible en: www.ipcc.ch/pdf/assessment-report/ar4/syr/ ar4_syr_sp.pdf

Helfand, G. \& Peyton, J., “A conceptual model of Environmental Justice”. En: Social Science Quarterly, Volume 80, Number 1 (March 1999), pp. 68-83.

Hill, B., Environmental Justice. Legal Theory and Practice (Environmental Law Institute Press, Washington DC, 2009), $482 \mathrm{pp}$.

Holder, J. \& Lee, M., Environmental Protection, Law and Policy, Second Edition (Cambridge University Press, 2007), 772 pp.

Holder, J., "Building Spatial Europe: An Environmental Justice Perspective", en Scott, J. (Ed.), Environmental Protection: European Law and Governance (Oxford University Press, 2009), pp. 92-126.

Kuehn, R., "A Taxonomy of Environmental Justice”. En: Environmental Law Reporter, Vol. 30, 2000, pp. 10681-10703.

National Academy of Public Administration, EPA, Addressing Community Concerns: How Environmental Justice relates to Land Use Planning and Zoning, Estados Unidos, Julio 2003. Disponible en: www.napawash.org/resources

National Environmental Justice Advisory Council, Meaningful Involvement and Fair Treatment by Tribal Environmental Regulatory Programs, Noviembre, 2004. Disponible en: www.epa. gov/compliance/resources/publications/ej/nejusticia ambientalc/ips-final-report.pdf 
Paterson, M., "Principles of Justice in the Context of Global Climate Change“. En: Luterbacher, U. \& Sprinz, D. (Eds.), International Relations and Global Climate Change (The MIT Press, Cambridge Massachusetts, London, England, 2001), pp. 119-126.

Sabatini, F. y Sepúlveda, C. (Eds.), Conflictos Ambientales. Entre la Globalización y la Sociedad Civil (Publicaciones CIPMA), 1997, 383 pp.

Salkin, P., "Environmental Justice and Land Use Planning and Zoning". En: Government Law Center of Albany Law School, Spring 2004, Government Law. Disponible en: www.governmentlaw.org

Salkin, P., "Intersection between Environmental Justice and Land Use Planning". En: Planning E Environmental Law, May 2006, Vol. 58, No 5, pp. 3-9.

Schlosberg, D. Defining Environmental Justice. Theories, Movements, and Nature (Oxford University Press, 2007), 238 pp.

Schwarte, C. \& Adebowale, M., Environmental Justice and Race Equality in the European Union (Capacity Global, 2007). Disponible en: www.capacity.org.uk

Shrader-Frechette, K., Environmental Justice. Creating Equality, Reclaiming Democracy (Oxford University Press, 2002), 269 pp.

Slater, A. \& Pedersen, O., "Environmental justice: lessons on definition and delivery from Scotland", Journal of Environmental Planning and Management, 2009, 52:6, pp. 797-812.

Universidad Diego Portales, Informe Anual sobre Derechos Humanos en Chile 2007. Hechos 2006. Capitulo de Medio Ambiente (Santiago, 2007), pp. 161-212.

Universidad Diego Portales, Informe Anual sobre Derechos Humanos en Chile 2008. Hechos 2007. Capítulo de Medio Ambiente (Santiago, 2008), pp. 505-538.

Vicente Giménez, T. (coordinadora), Justicia Ecológica y Protección del Medio Ambiente (Editorial Trotta, Madrid, 2002), 285 pp.

Wiegandt, E., "Climate Change, Equity and International Negotiations". En: Luterbacher, U. \& Sprinz, D. (Eds.), International Relations and Global Climate Change (The MIT Press, Cambridge Massachusetts, London, England, 2001), pp. 126-150. 